\title{
Lichen Sclerosus in Breast Cancer Survivor
}

\author{
Pedro Vieira-Baptista, MD \\ Clínica da Mulher, Serviço de Ginecologia e Obstetrícia, Hospital de São João, Porto, Portugal.
}

$\mathrm{J}$ Gen Intern Med 28(3):344

DOI: $10.1007 / \mathrm{s} 11606-012-2319-7$

(c) Society of General Internal Medicine 2013

To the Editors:-First of all, we would like to congratulate the authors and the JGIM for publishing on such a poorly known subject, even among gynecologists. However, there are some points defended in this article which we believe to be questionable.

The article asserts that lichen sclerosus (LS) is more frequent in low estrogen states, ${ }^{1}$ but one cannot conclude that there is a direct relation. It actually has a bimodal distribution (prepubertal and postmenopausal), but an early menopause does not seem to be a risk factor. The supposed amelioration of affected girls in puberty is nowadays put in question. $^{2}$

Hormonal replacement therapy and oral contraceptives do not seem to ameliorate the symptoms. There is also no evidence of any variation of symptoms during pregnancy or menses. ${ }^{3}$ Therefore, we do not believe that aromatase inhibitors pose patients at greater risk for LS. However, these patients might still need additional gynecological appointments, namely because of vaginal atrophy, as referred. There is no evidence that treatment will stop anatomical changes or avoid progression to vulvar intraepithelial neoplasia (VIN) and cancer.

It is difficult to ascertain what is meant by "advanced lichen sclerosus", since there is no current classification of it. However, believing it was a case of severe scarring and atrophy, we must consider that this condition was probably present for several years (even if asymptomatic), and the process probably began longer than the referred 3.5 years taking anastrozol.

We would also like to comment that the latest classifications of the International Society for the Study of Vulovaginal Disease (ISSVD) ${ }^{4}$ recommend that this entity should be called "lichen sclerosus", dropping the "et atrophicus", as not all cases occur with atrophy. As far as we know, there is no known association between hepatitis $\mathrm{C}$ virus (HCV) and LS in women; there is some evidence of a possible association, but it concerns lichen planus (LP) and especially oral rather than vulvovaginal LP.

There is growing evidence of an association of LS with autoimmune disease, namely thyroiditis. ${ }^{5}$ We believe that thyroid disease screening should be part of the standard management of these patients.

Corresponding Author: Pedro Vieira-Baptista, MD; Clínica da Mulher, Serviço de Ginecologia e Obstetrícia, Hospital de São João, 4200-319 Porto, Portugal (e-mail: pedrovieirabaptista@gmail.com).

\section{REFERENCES}

1. Potter JE, Moore KA. Lichen Sclerosus in a Breast Cancer Survivor on an Aromatase Inhibitor: A Case Report. J Gen Intern Med. 2013: doi: 10.1007/s11606-012-2318-8.

2. Powell J, Wojnarowska F. Childhood vulvar lichen sclerosus. The course after puberty. J Reprod Med Sep. 2002;47(9):706-9.

3. Marren P, Cherry C, Day A, et al. Lichen sclerosus: the patient, the hormonal influences and disease impact. Br J Dermatol. 1995;21:133.

4. Lynch PJ, Moyal-Barrocco M, Bogliato F, Micheletti L, Scurry J. 2006 ISSVD classification of vulvar dermatoses: pathological subsets and their clinical correlates. J Reprod Med J Reprod Med. 2007;52(1):3-9.

5. Birenbaum DL, Young RC. High prevalence of thyroid disease in patients with lichen sclerosus. J Reprod Med. 2007;52(1):28-30. 